\title{
SILVER CONCENTRATIONS IN COLORADO, USA, WATERSHEDS USING IMPROVED METHODOLOGY
}

\author{
Liang-Saw Wen, $\dagger+$ Peter H. Santschi, $*+$ Gary A. Gill,$\dagger$ and Degui Tang $\dagger \S$ \\ $\dagger$ Department of Oceanography, Texas A\&M University, Galveston, Texas 77551, USA \\ $\$$ National Center for Ocean Research, National Taiwan University, P.O. Box 23-13, Taipei, Taiwan, Republic of China \\ $\S$ Water Chemistry Program, University of Wisconsin, 660 North Park Street, Madison, Wisconsin 53706-1484, USA
}

(Received 2 August 2001; Accepted 22 March 2002)

\begin{abstract}
River water samples were collected at five sites in the state of Colorado, USA, to assess the impact of municipal and industrial discharges on Ag concentrations and speciation in surface waters. Samples were collected and analyzed for total (unfiltered collections), filtered $(0.1$ and $0.4 \mu \mathrm{m})$, particulate $(\geq 0.45 \mu \mathrm{m})$, and colloidal $\mathrm{Ag}(3 \mathrm{kDa}-0.1 \mu \mathrm{m})$ using ultraclean protocols. A series of laboratory experiments were conducted to assess bias from sample storage, digestion, and preconcentration protocols. In general, upstream unfiltered and particulate $\mathrm{Ag}$ concentrations fell within a fairly narrow range, 3.1 to $21 \mathrm{ng} / \mathrm{L}$ and 0.2 to $1.7 \mu \mathrm{g} /$ $\mathrm{g}$, respectively. Downstream unfiltered and particulate $\mathrm{Ag}$ concentrations showed a more broad range, 2.8 to $1,110 \mathrm{ng} / \mathrm{L}$ and 0.5 to $104 \mu \mathrm{g} / \mathrm{g}$, respectively, and reflected attenuated impacts of Ag-laden discharge effluents. However, Ag concentrations in the 0.1$\mu \mathrm{m}$ filter-passing fraction 0.8 to $1.2 \mathrm{~km}$ downstream from major treatment plant effluents were all below the chronic silver criteria. On average, more than $60 \%$ of the $0.1-\mu \mathrm{m}$ filter-passing Ag was associated with colloidal macromolecular organic matter. Silver concentrations in colloids $(\mu \mathrm{g} / \mathrm{g})$ were, on average, the same as those in suspended particulate matter. The percentage abundance of colloidal Ag was similar to that of dissolved organic carbon, suggesting that strong Ag binding ligands exist in both the colloidal and the particle size fractions, as these macromolecular ligands likely play a major role in Ag speciation.
\end{abstract}

Keywords-Silver Speciation Colloids Freshwater Colorado

\section{INTRODUCTION}

Chemical and phase speciation of trace elements is key to understanding the factors controlling their biogeochemical cycling and toxicity and bioavailability to organisms within natural aquatic systems. Trace metal concentrations in aquatic systems are regulated by a multitude of factors, including physical (mixing), chemical (redox, complexation), biological (uptake by biota), and geological (sorptive uptake by mineral phases suspended in the water) processes. All these factors, acting in concert, usually result in very low concentrations at $\mathrm{nM}$ and pM levels for many trace metals. However, even at these low concentrations, it might be possible that they can exert negative effects on aquatic biota [1]. The U.S. Environmental Protection Agency (U.S. EPA) acute criteria for freshwater is $34 \mathrm{nM}(3 \mu \mathrm{g} / \mathrm{L})$ at a hardness of $100 \mathrm{mg} / \mathrm{L}$. Laboratory data using $\mathrm{AgNO}_{3}$ indicate effects can occur at $\mathrm{Ag}$ concentrations as low as $2 \mathrm{nM}(0.2 \mu \mathrm{g} / \mathrm{L})$ [1]. However, natural organic matter and metastable sulfide and thiol complexes are thought to provide protective effects.

Silver $(\mathrm{Ag})$ is considered one of the more toxic elements and is regulated by U.S. EPA and state agencies at nM levels [2]. Environmental regulations do not, however, regulate the toxic, free, or labile forms of metals and rely mostly on concentrations in the solution passing a $0.45-\mu \mathrm{M}$ filter that also contain colloidal, macromolecular organic matter and mineral phases. Hence, interest is increasing in colloids and organic complexes of trace elements in natural waters [e.g., 3-9].

Silver is often introduced into the aquatic environment from municipal and industrial water treatment plants receiving liquid wastes from the photographic industry. Thereafter, Ag has

* To whom correspondence may be addressed (santschi@tamug.tamu.edu). the potential to be a major urban pollution indicator [8-10]. Very few reliable measurements exist of the background Ag content of natural waters because of the difficulty of collecting and analyzing Ag at ultratrace levels (parts per trillion, ng/L). Smith and Flegal [10] report that dissolved $(<0.45 \mu \mathrm{m}) \mathrm{Ag}$ in San Francisco Bay (CA, USA) estuary ranges from 6 to $250 \mathrm{pM}(0.65-27 \mathrm{ng} / \mathrm{L})$. Coastal California waters have a background Ag concentration near 3 pM [8]. In Texas, USA, rivers and estuaries, total $\mathrm{Ag}$ concentrations ranged between $<1$ and $10 \mathrm{ng} / \mathrm{L} \mathrm{[4,9].} \mathrm{Few} \mathrm{reliable} \mathrm{reports} \mathrm{exist} \mathrm{of} \mathrm{Ag}$ in freshwater systems where ultraclean sampling and analytical protocols were followed. Shafer et al. [11] report total Ag concentrations for 22 rivers in Wisconsin, USA, ranging from 1.2 to $72 \mathrm{ng} /$ L. In the Quinnipiac River (CT, USA), Benoit [12] observed total $\mathrm{Ag}$ concentrations ranging from $<10 \mathrm{ng} / \mathrm{L}$ in headwater streams to $500 \mathrm{ng} / \mathrm{L}$ downstream of industrial and municipal discharge points. Our previous work in Texas watersheds revealed that both total and filter-passing $(0.1-$ and $0.4-\mu \mathrm{m}$ pore size) Ag concentrations spanned two orders of magnitude [4]. This wide range in concentrations reflects the diverse environmental settings encountered, ranging from pristine waters with no known Ag inputs to waters impacted by discharges from major urban areas. However, as pointed out in Santschi [13], $\operatorname{Ag}(\mathrm{I})$ removal rates in freshwater environments are fast, with one to two weeks half-removal times even in pristine environments, such as the Canadian shield lakes. Furthermore, the extent of $\operatorname{Ag}(\mathrm{I})$ sorption to freshwater suspended matter is high and rather insensitive to $\mathrm{pH}$ down to a $\mathrm{pH}$ of 4.8 [14].

This paper describes results on the concentration and chemical and phase speciation of $\mathrm{Ag}$ in five Colorado river systems with respect to discharge inputs. Different ultrafiltration systems were used to constrain colloidal Ag. Because one could 
argue that low Ag values found in most aquatic samples are a consequence of inadequate procedures, such as wall sorption losses during or after sampling, several laboratory studies were conducted. The extent and kinetics of $\mathrm{Ag}$ adsorption losses to various container walls during sample storage at ambient $\mathrm{Ag}$ concentrations were thus thoroughly tested before and after sampling.

\section{METHODOLOGY AND APPROACHES}

\section{Sampling locations and sample collections}

The five locations and six plants (CO, USA) (Table 1) were chosen to provide Ag concentrations from diverse sources. All the sites, except Estes Park, had a Ag discharge limit in their discharge permit. Colorado Springs was chosen to demonstrate that the Ag recovery program, which removes Ag at the source of generation before discharge to the sewer, implemented several years earlier, resulted in lower silver concentrations in the plant effluent than a plant without such pollution prevention techniques (e.g., the two Ft. Collins plants: Mulberry Water Treatment Facility and Drake Water Treatment Facility; see Table 1). The Kodak facility was chosen because the silver concentrations were known to be higher than wastewater treatment plants (WWTPs) of publicly owned treatment works (POTWs) but also to show that silver was bound to organic and particulate matter present in the effluent, thus being quickly removed from the water, thereby becoming less available to aquatic organisms. The Henderson Mine site was chosen to show that little Ag should be present in the effluent and downstream because of the removal technique used at the site. The Estes Park POTW site was chosen as a control site with no known industrial contributions of Ag, with only Ag from domestic waste.

River water sampling was targeted for site locations upstream (0.8-1.2 km away), downstream (0.8-1.2 km away), and at a discharge point of wastewater effluent into a riverine system in the state of Colorado during October 1996. The sampling locations monitored for this study were the Cachela-Poudre River at the Kodak Colorado Facility in the city of Windsor and also at the Mulberry and Drake water treatment facilities in Fort Collins. The Upper Big Thompson River was sampled at the Estes Park wastewater treatment facility in Estes Park. Sampling of Fountain Creek in Colorado Springs was conducted at the Colorado Springs Wastewater Treatment Facility and the No. 4 Diversion Canal. In addition, monitoring of the Cyprus Climax Metal Company's Henderson Mine near Empire was conducted upstream of the Upper Urad Reservoir, the URAD 004 outfall, the Henderson Mine effluent, and at $\mathrm{U} 2$, downstream of the reservoir spillway. Sample locations are listed in the Table 1.

State-of-the-art ultraclean techniques were used during all stages of sample collection, transport, handling, processing, and analysis [3-5]. Both filtered and unfiltered samples were collected using a peristaltic pump system equipped with Teflon ${ }^{\circledR}$ tubing inlets and outlets. For sample collection, the tubing was attached to a nonmetallic pole and the tubing inlet oriented into the current at about $0.25 \mathrm{~m}$ depth to obtain water untouched by the sampling apparatus. Prior to sample collection, the sampling system was flushed for 5 to $10 \mathrm{~min}$ at a flow rate of approximately $300 \mathrm{ml} / \mathrm{min}$ to remove any residual acid in the tubing lines from the cleaning process. Unfiltered samples were drawn directly into acid-cleaned Teflon bottles. Filtered samples were obtained by attaching an acid-cleaned polyethylene membrane cartridge $(0.45$ and $0.1 \mu \mathrm{m}$; MSI Micron
Separations, Westboro, MA, USA) to the pump outlet and dispensing the water directly into an acid-cleaned Teflon bottle. Sample bottles were transported to the field in double plastic bags (inner bag acid cleaned), filled with $1 \%$ triple-distilled $\mathrm{HNO}_{3}$. Sample bottles were handled in the field only by personnel wearing Class-100 compatible plastic vinyl gloves (OAK Technical, Stow, OH, USA). Samples for Ag determination were acidified with triple-distilled $\mathrm{HNO}_{3}\left(2 \mathrm{ml} \mathrm{HNO}_{3}\right.$ per $1 \mathrm{~L}$ of sample) to a final $\mathrm{pH}$ of approximately 1.5 within $8 \mathrm{~h}$ of collection under the protection of a Class-100 clean-air bench.

A parallel filtration was carried out to collect suspended particulate matter (SPM) by drawing water through preweighed, acid-cleaned, 47-mm diameter, 0.45- $\mu \mathrm{m}$ polycarbonate membranes (Nuclepore, Cambridge, MA, USA) held within a TEFZEL filter assembly (Savillex, Minnetonka, MN, USA) $[4,5]$. The sampling units were prepared and processed in a Class-100 trace metal clean laboratory, using triple-distilled, subboiling quartz distilled reagents. For a chemical speciation study, separate samples ( $1 \mathrm{~L}$ vol) were collected for general characterization of water chemical parameters using the same peristaltic pump and filtration equipment $(0.45 \mu \mathrm{m})$ as that used for the collection of $\mathrm{Ag}$ samples. Samples were collected for the determination of $\mathrm{pH}$, alkalinity, hardness, total suspended solids, major ions $\left(\mathrm{Cl}^{-}, \mathrm{SO}_{4}^{2-}, \mathrm{NO}_{3}^{-}, \mathrm{Mg}^{2+}, \mathrm{Ca}^{2+}\right.$, $\mathrm{Na}^{+}$, and $\mathrm{K}^{+}$), and dissolved organic carbon (DOC). For the phase speciation study, ultraclean, cross-flow ultrafiltration (CFUF) systems (3-kDa cutoff; AMICON Miniplate; Millipore ${ }^{\circledR}$, Bedford, MA, USA) were used, applying previously documented procedures for isolating both colloidal organic carbon and trace metals [3].

\section{Determination of silver and other parameters}

Aqueous samples were preconcentrated under Class-100 clean laboratory conditions for the determination of total (unfiltered), filter-passing (0.1 and $0.45 \mu \mathrm{m})$, colloidal (3 $\mathrm{kDa}-$ $0.1 \mu \mathrm{m})$, and truly dissolved $(<3 \mathrm{kDa}) \mathrm{Ag}$ concentrations using a modified version of the ammonium 1-pyrrolidine dithiocarbamate/diethyldithiocarbamate (APDC/DDDC) solvent extraction method reported previously [4]. Prior to preconcentration, filtered and acidified $\left(\mathrm{HNO}_{3}\right.$ to $\mathrm{pH}$ of 1.5$)$ water samples were pretreated (in their original Teflon PFA sample bottle) using ultrasonification for $60 \mathrm{~min}$ at $60^{\circ} \mathrm{C}$, followed by ultraviolet (UV) irradiation with a bank of UV lamps (120 W) for $24 \mathrm{~h}$ to photooxidize organic matter. Silver measurements were carried out on a Perkin-Elmer 5100 graphite furnace atomic absorption spectrophotometer (GFAAS) equipped with Zeeman background correction (Perkin-Elmer, Wilton, CT, USA). Silver determinations were conducted utilizing the method of standard additions to correct for sample matrix interferences. Procedure blanks and spiked samples were run with each set of samples extracted to determine yield correction factors and detection limit capabilities. The detection limit for $\mathrm{Ag}$ measurements, based on three times the standard deviation of a blank signal, combined with a sample preconcentration factor of 50-fold, was $10 \mathrm{pg} / \mathrm{L}$. Standard additions of Ag to water samples yielded recoveries of $97 \pm 2 \%(n=9)$ after UV digestion and APDC/DDDC solvent extraction. The precision of triplicate analysis was better than $3 \%$ (relative standard deviation [RSD]). Procedure blanks were all below the detection limit. Direct analysis of standard reference water 1643c (National Institute of Standards and Technology, Standard Reference Materials Program, Gaithersburg, MD, USA), 
without preconcentration, gave $2.22 \pm 0.02 \mathrm{ng} / \mathrm{L}$. The certified value for $\mathrm{Ag}$ is $2.21 \pm 0.30 \mathrm{ng} / \mathrm{L}$.

Filters containing particulate material were placed in acidcleaned petri dishes on the clean bench to dry. The filters were reweighed to determine the particle mass collected. Particles were then leached or digested in a Teflon digestion vessel using a three-step procedure [4] to characterize the solid-phase speciation of trace metals among a number of operationally defined host fractions. Leaching agents included 4.5 $\mathrm{N}$ highpurity acetic acid (Q-HAc) to release weakly adsorbed Ag; an acid mixture consisting of high-purity $2 \mathrm{~N} \mathrm{HCl}(\mathrm{Q}-\mathrm{HCl})$ and high-purity $1 \mathrm{~N} \mathrm{HNO}_{3}\left(\mathrm{Q}-\mathrm{HNO}_{3}\right)$ for releasing $\mathrm{Ag}$ associated with organics, Fe-Mn oxyhydroxide, and some sulfidic phases, such as $\mathrm{FeS}$; and an acid mixture $(2: 2: 1)$ consisting of concentrated $\mathrm{Q}-\mathrm{HNO}_{3}, 6 \mathrm{~N} \mathrm{Q}-\mathrm{HCl}$, and concentrated high-purity hydrofluoric acid (Q-HF) for releasing Ag associated with refractory phases, such as silicates and $\mathrm{FeS}_{2}$. Silver was then quantified in the digestion matrix using GFAAS, as described for aqueous samples.

Major cations were determined using flame atomic absorption spectrometry (FAAS) and major anions by ion chromatography (Dionex, Sunnyvale, CA, USA). Dissolved organic carbon measurements were carried out using a Shimadzu TOC5000 high-temperature catalytic combustion analyzer (Shimadzu Scientific, Columbia, MD, USA). Total suspended solids concentrations were determined by filtration $(0.45 \mu \mathrm{m})$ of a known sample volume onto a preweighed polycarbonate membrane, drying, and reweighing the membrane. Alkalinity and hardness measurements were conducted using standard titration methods [15]. Conductivity, temperature, and $\mathrm{pH}$ were measured in the field using an ion-selective electrode immediately after calibration with standard buffer solutions.

\section{Sample storage and digestion experiments}

A series of laboratory experiments were conducted to address concerns that low ambient Ag concentrations (and other trace elements) might arise from adsorption of $\mathrm{Ag}$ ions onto the container walls of a storage bottle ([16] and references therein) during the period between collection and analysis. Two types of experiments were conducted: radiotracer experiments with tap, laboratory, and natural water samples and stable Ag measurements using natural water samples.

Radiotracer storage experiments. Radiotracer experiments were conducted at room temperature using Teflon bottles stored on the laboratory bench under various pretreatment conditions. These experiments were designed to simulate typical sample conditions prior to analysis. A river water sample was collected from the downstream site at Colorado Springs and was refiltered using a $0.45-\mu \mathrm{m}$ membrane filter prior to beginning the experiments. Samples in 0.5- or 1-L Teflon bottles were spiked with ${ }^{110 \mathrm{~m}} \mathrm{Ag}$ radioisotope at tracer levels $(\leq 1 \mu \mathrm{g} / \mathrm{L})$ and stored for a two-month period. Time-series subsamples were drawn into 10-ml scintillation vials (except for experiment E). Four different aqueous solutions were followed simultaneously: high-purity laboratory deionized water (experiment A), tap water (experiment B), unacidified river water (experiments $\mathrm{C}$ and $\mathrm{E}$ ), and acidified river water (experiment D). High-purity concentrated $\mathrm{HNO}_{3}$ (SeaStar, Victoria, BC, Canada) was used for sample acidification. The Teflon bottles used for these experiments were acid cleaned [3] in an identical manner to those used for the field sampling in Colorado. Following the twomonth storage period, all the samples were subjected to several treatments to determine whether any adsorbed Ag could be
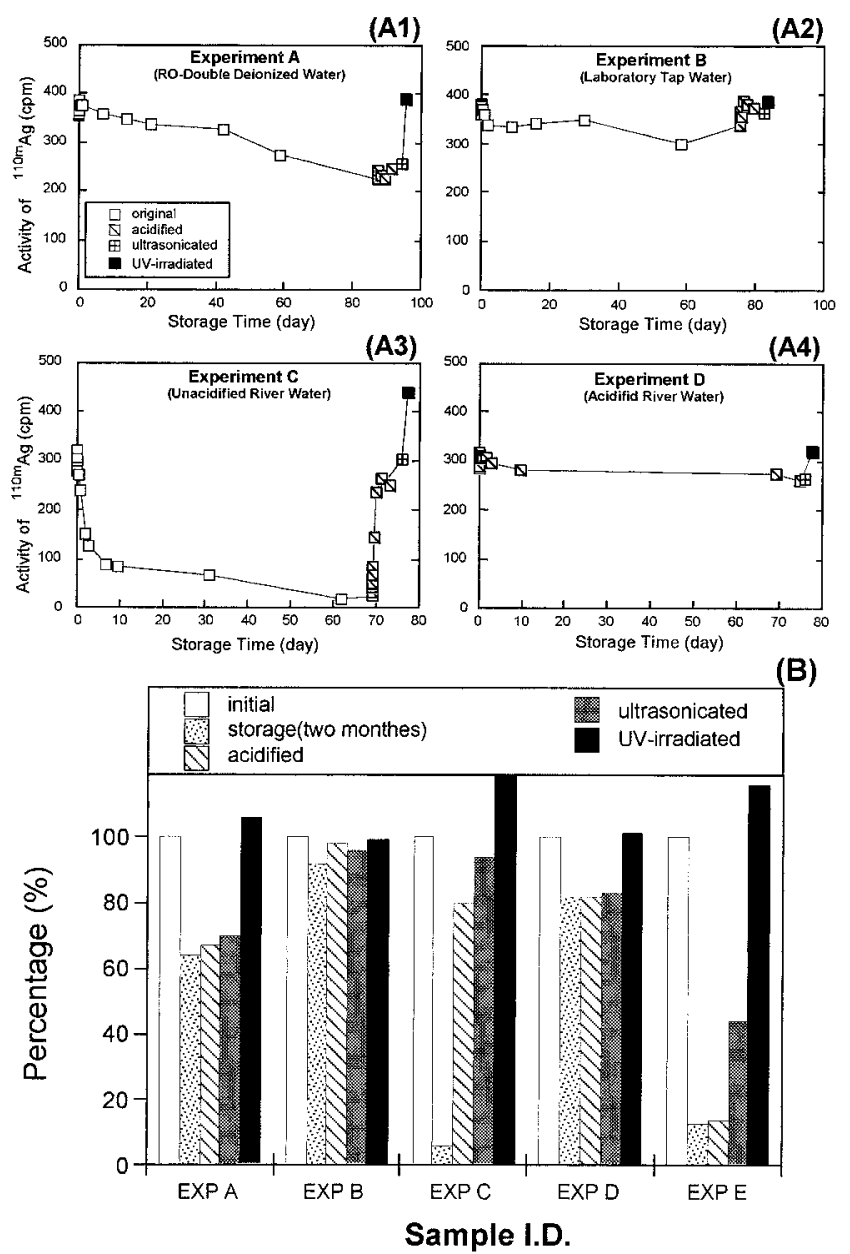

(B)

Fig. 1. (A) Time-course measurements of the radioisotope ${ }^{110 \mathrm{~m}} \mathrm{Ag}$ spiked at tracer levels into Colorado River (USA) water under four different storage conditions. (B) Final recoveries after different treatments. $\mathrm{RO}=$ reverse osmosis; $\mathrm{ID}=$ sample type.

released from the bottle walls by either additional acidification with $\mathrm{HNO}_{3}$, ultrasonification for $1 \mathrm{~h}$ at $60^{\circ} \mathrm{C}$, or whole-bottle UV treatment for $24 \mathrm{~h}$ using a bank of six $25-\mathrm{W}$ UV lamps. The results of this adsorption experiment are summarized in Figure 1. Desorption from the walls is evident at the end of the experiment, when $\mathrm{HNO}_{3}$ was added to the sample to a final $\mathrm{pH}$ of 1.5 .

Natural water storage experiments. The second storage experiment was conducted using replicate filtered water $(0.45$ $\mu \mathrm{m})$ samples collected in 1- and 2-L Teflon bottles from the Colorado Springs downstream site. Different experimental conditions were used on four sets of replicate samples to test various scenarios of adsorption loss. One set of samples was acidified and extracted using the APDC/DDDC organic extraction methodology (described previously) in the field within $2 \mathrm{~h}$ of collection under the protection of a Class-100 clean air bench (immediate extraction). This collection should lead to minimal adsorptive losses because of the short time interval between collection and extraction. A separate pair of samples were treated in exactly the same fashion as all the other samples for this project; they were acidified in the field, transported back to the laboratory, and analyzed after approximately a twomonth storage period (in-lab extraction 1). A third sample set was left unacidified and transported back to the laboratory. Following approximately a four-month storage period, part of 


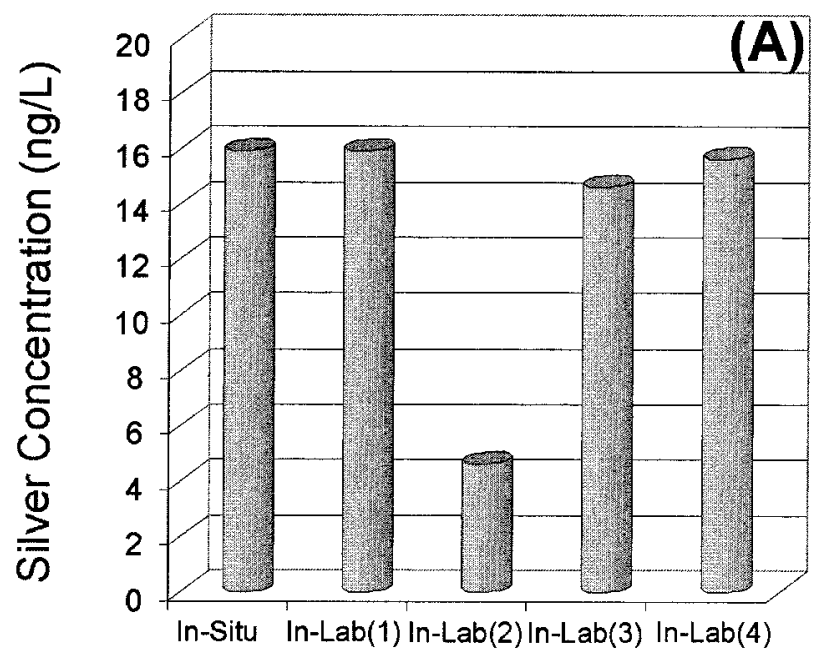

Sample I.D.
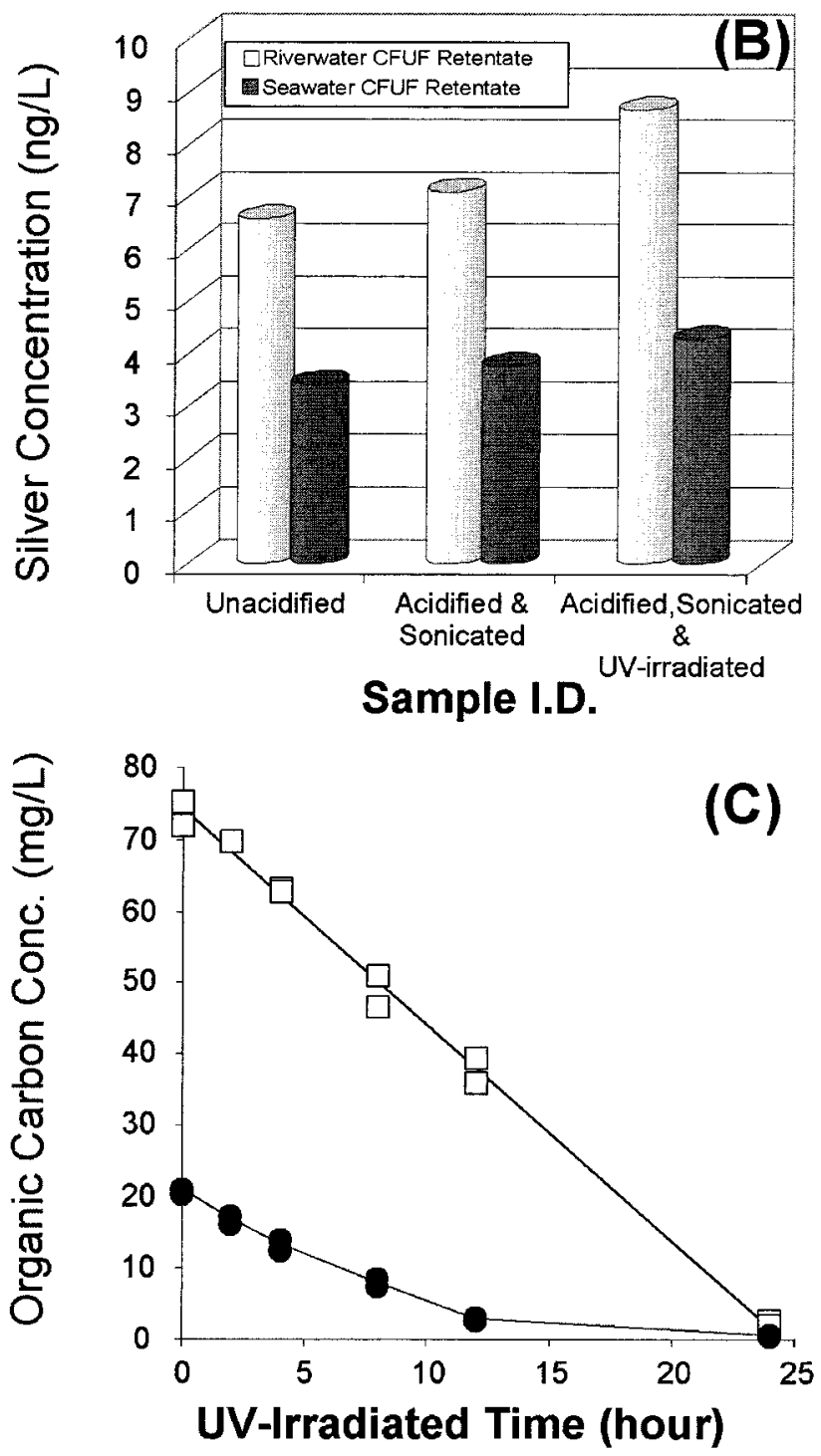

Fig. 2. (A) Results of Ag concentration in sample storage experiment of river water. (B) Results of various digestion procedures for measurements of $\mathrm{Ag}$ concentration in $>1 \mathrm{kDa}$ retentate water samples concentrated by cross-flow ultrafiltration (CFUF). (C) Time-series results of dissolved organic carbon concentration in CFUF concentrated ( $>1 \mathrm{kDa}$ retentate) water sample when exposed to UV-irradiated digestion procedure. ID $=$ sample type. the samples were extracted without any acidification or digestion (in-lab extraction 2), and the companion samples were ultrasonicated (without any acidification) for $1 \mathrm{~h}$ and UV digested for $24 \mathrm{~h}$ prior to Ag determination (in-lab extraction 3 ). The final set of samples, which were left unacidified for a four-month storage period, were acidified, ultrasonified, and UV digested, and the Ag content was determined (in-lab extraction 4). A summary of the Ag content in these four storage and processing treatments is given in Figure 2A.

$U V$-digestion studies. The ability of the UV-digestion method to release Ag from colloidal material prior to sample preconcentration was investigated using colloids (1 kDa CFUF retentate) obtained from two different sources, the Trinity River $(S=0 \%$ ) and Galveston Bay (TX, USA) $(S=30 \%$ ). Four different sample treatments were compared. First, retentates were extracted immediately after ultrafiltration without any digestion procedure. Second, retentates were acidified and sonicated immediately after ultrafiltration and subsequently extracted. Third, retentates were acidified, ultrasonicated, and UV digested after ultrafiltration and extracted. Fourth, retentates collected in a 250-ml Teflon bottle were subjected to UV digestion. Time-series subsamples were drawn for determination of organic carbon concentration as a function of digestion time. The Trinity River filtered $(<0.45 \mu \mathrm{m})$ water sample had a colloidal organic carbon (COC) concentration of 3.4 $\mathrm{mg} / \mathrm{L}$, while the surface water sample from the Gulf of Mexico had a COC content of $1.1 \mathrm{mg} / \mathrm{L}$. A summary of the $\mathrm{Ag}$ and carbon content in these four experimental treatments is given in Figure 2.

Storage bottle composition tests. An adsorption experiment was conducted to determine whether the type of sample bottle material used to store low-level water samples for Ag influenced the Ag concentration during short-term ( one week) storage. The bottle materials investigated included FEP Teflon, polyvinylchloride (PVC), polycarbonate (PC), polypropylene (PP), low- and high-density polyethylene (LDPE and HDPE), and fluorinated polyethylene (FLPE) (Nalgene, Rochester, NY, USA). Two types of aqueous solutions were used, high-purity laboratory water of different acid strengths and spiked with Ag to a concentration of $1 \mu \mathrm{g} / \mathrm{L}$ and filtered $(<0.4 \mu \mathrm{m})$ natural Trinity River water, which had an ambient Ag concentration of $0.70 \mu \mathrm{g} / \mathrm{L}$. The solutions were placed into three separate 250-ml bottles and time-series samples drawn from each bottle for determination of $\mathrm{Ag}$ for a total storage period of one week. Results of the Ag concentrations in these two experiments are given in Figure 3 and Appendix 1.

\section{RESULTS AND DISCUSSION}

\section{Storage and digestion}

Figure 1A shows the time-course measurements of ${ }^{110 \mathrm{~m}} \mathrm{Ag}$ activity in each test solution of radiotracer adsorption experiments. The initial adsorption rate was highest in unacidified river water compared to distilled water (DI) and tap water. After $70 \mathrm{~d}$ of storage, adding additional acid and ultrasonification did little to remove $\mathrm{Ag}$ from the bottle walls in all test solutions (Fig. 1). However, ultrasonification combined with UV irradiation released absorbed Ag from the bottle walls to solution, and all the original ${ }^{110 \mathrm{~m}} \mathrm{Ag}$ spiked into the bottle was recovered (Fig. 1B). Recoveries exceeded $100 \%$ because the absorbed Ag was returned to a final solution volume smaller than initially present. The extent of Ag loss to the wall after two months was different in each experiment (Fig. 1B). About $40 \%$ loss of Ag occurred in solution in unacidified laboratory 


\section{Double Deionized Water (A)}
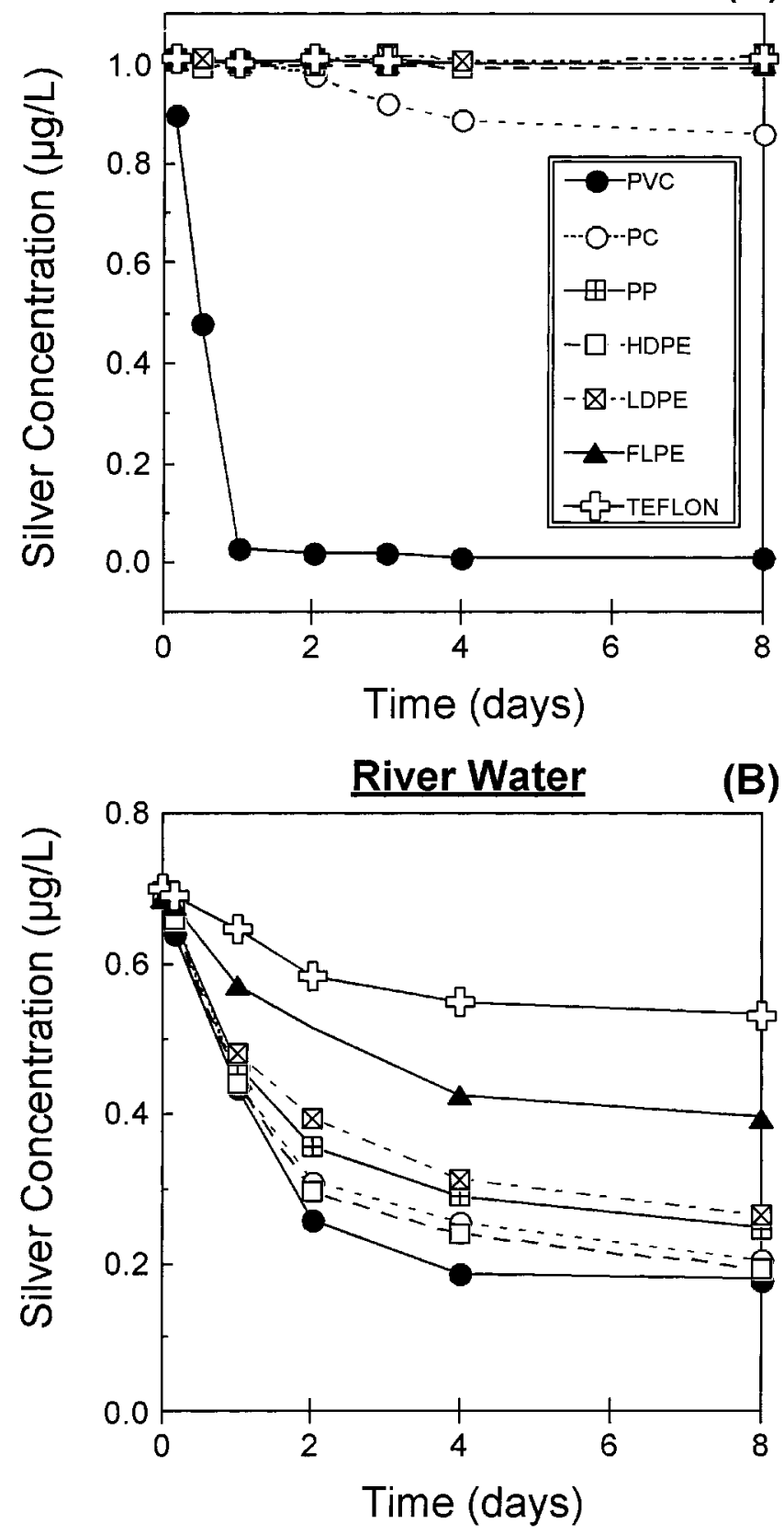

Fig. 3. Selective Ag adsorption behavior onto bottle walls and/or contamination artifacts observed for various plastic materials during storage of natural and laboratory water samples. (A) Results of Ag in double-distilled water. (B) Results of $\mathrm{Ag}$ concentration in river water. The bottle materials investigated included FEP Teflon, polyvinylchloride (PVC), polycarbonate (PC), polypropylene (PP), lowand high-density polyethylene (LDPE and HDPE), and fluorinated polyethylene (FLPE).

DI water, 20\% loss in unacidified tap water, $20 \%$ loss in acidified river water, and $90 \%$ loss of $\mathrm{Ag}$ in the unacidified river water samples. All samples without initial acidification showed loss of Ag to the bottle walls in less than $24 \mathrm{~h}$, which could not be recovered by subsequent acidification after the storage period. However, including UV irradiation in the sample treatment after storage consistently achieved $100 \%$ recovery of the initial Ag spike (Fig. 1B), suggesting that wall adsorption was mediated (or caused) by surface-active natural organic matter.

In the stable Ag storage experiments, we found that in situ extraction or in situ acidification resulted in identical Ag concentrations (Fig. 2A). Even if samples were not acidified immediately, after three months, all the Ag could be recovered by combining acidification with UV irradiation (Fig. 2A). In natural waters and wastewaters, colloidal and low-molecularweight organic compounds often sequester analytes and must be destroyed by appropriate treatment prior to analysis $[5,17-$ 20]. Our experimental results clearly document the necessity of using UV irradiation as a digestion procedure prior to sample preconcentration (Fig. 2B). Colloidal samples processed without a UV-digestion procedure usually exhibited considerably lower recovery even with acidification and ultrasonification (Fig. 2B). Dissolved organic carbon in UV-digested samples was undetectable after $24 \mathrm{~h}$ of UV irradiation. During irradiation, DOC concentrations linearly decreased during the exposure time (Fig. 2C).

Listed in Appendix 2 are the results of Ag adsorption experiments with different bottle materials. After $8 \mathrm{~d}$ of storage, Ag-spiked high-purity laboratory water stored in PVC and PC bottles without acidification showed decreasing Ag concentrations (Fig. 3A). River water samples without acidification also showed considerable Ag losses, regardless of the type of bottle material (Fig. 3B). Even with a normal acidification scheme (2-ml concn. $\mathrm{HNO}_{3}$ per $1 \mathrm{~L}$ of sample water), considerable amounts of $\mathrm{Ag}$ in river water were lost to the walls of PVC bottles. The extent of Ag loss to the bottle walls was different for each type of material, with an absorption loss sequence of $\mathrm{PVC}>\mathrm{HDPE}>\mathrm{PC}>\mathrm{PP}>\mathrm{LDPE}>\mathrm{FLPE}>$ Teflon. These results also indicate that when samples are properly (2-ml concn. $\mathrm{HNO}_{3}$ per $1 \mathrm{~L}$ of sample water) acidified, most of the plastic bottles, with the exception of PVC, can be used for short-term storage of aqueous samples for low-level Ag determination. However, for long-term storage, Teflon bottles give best results and thus are preferred. Moreover, Teflon readily passes a large percentage of UV radiation and is the only material that will not deteriorate when exposed to UV.

\section{Silver distribution in watersheds}

Concentrations of $\mathrm{Ag}$ in unfiltered, filter-passing ( 0.45 and $0.1 \mu \mathrm{m})$, and particulate fractions are illustrated for each sampling site in Figure 4, and values are given in Table 1. General water chemistry and water quality parameters are given in Table 1 and Appendix 2. The Ag concentrations in unfiltered samples spanned more than four orders of magnitude, from a high of 33,400 ng/L at the Kodak Colorado Division effluent to a low of $1.8 \mathrm{ng} / \mathrm{L}$ at outfall 004 (Henderson Mine; see Table 1). In general, upstream unfiltered Ag concentrations fell within a fairly narrow range of 3.1 to $21 \mathrm{ng} / \mathrm{L}$. Downstream unfiltered Ag concentrations were more broad, 2.8 to $1,107 \mathrm{ng} /$ $\mathrm{L}$, with the higher downstream concentrations being associated with higher Ag levels in discharge effluents. Filtered samples also had a wide range in Ag concentration, which generally mirrored that observed for the unfiltered samples, but at lower overall concentration levels. In all cases, the concentration of Ag observed in the $0.1-\mu \mathrm{m}$ filter-passing fraction was less than that observed in the $\leq 0.45-\mu \mathrm{m}$ fraction.

It is important to note that natural dilution and removal mechanisms are efficient enough to result in low (dissolved) $\mathrm{Ag}$ concentrations in the $\leq 0.1-\mu \mathrm{m}$ filter-passing fraction downstream from effluents. These low Ag concentrations at the downstream locations demonstrate, for example, that the Ag recovery program of the city of Colorado Springs is working well, resulting in $12 \mathrm{ng} / \mathrm{L}$ downstream of the treatment 


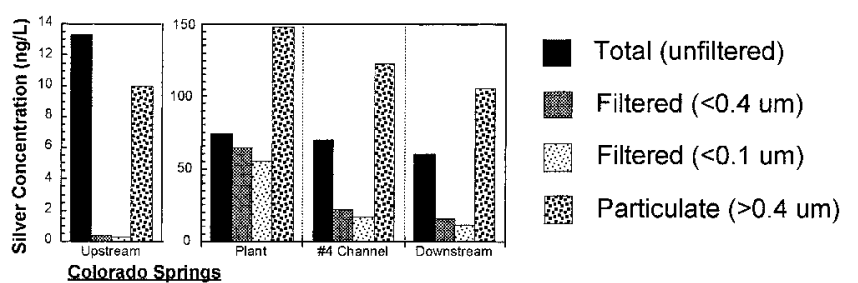

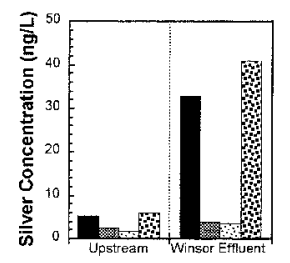

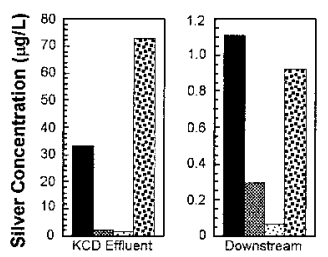

Kodak Colorado
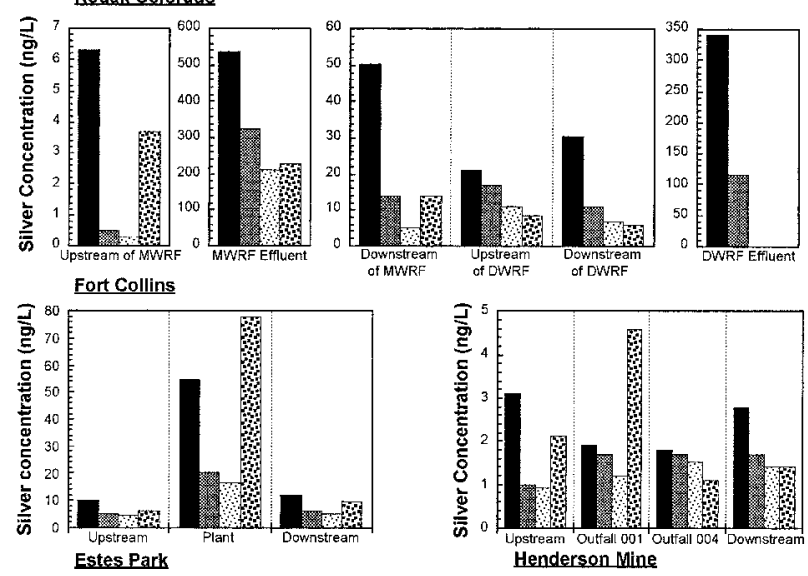

Fig. 4. Silver concentrations in unfiltered, filtered ( 0.1 and $0.45 \mu \mathrm{m})$, and particulate phases in Colorado, USA, river water. MWRF $=$ Mulberry Water Treatment Facility; DWRF $=$ Drake Water Treatment Facility; KCD $=$ Kodak Colorado Division. Sample locations are given in Table 1.

plant effluent (Table 1). Downstream of the other treatment plant effluents, the highest concentrations were usually (with the exception of the Kodak plant effluent) less than $12 \mathrm{ng} / \mathrm{L}$. Downstream from the Ft. Collins plant effluent, which operates without such pollution prevention techniques, resulted in 5 to $7 \mathrm{ng} / \mathrm{L}$. The highest $0.1-\mu \mathrm{m}$ filter-passing concentration of 70 ng/L was observed downstream from the Kodak plant effluent, still well below the silver criteria. These findings are important in light of the chronic value set by Colorado of $190 \mathrm{ng} / \mathrm{L}$ and the current freshwater acute dissolved criterion of $3.4 \mu \mathrm{g} / \mathrm{L}$ of Ag based on a hardness of $100 \mathrm{mg} / \mathrm{L}$ [2], resulting in a maximum ratio of the ambient concentration to the acute criterion of 0.02 .

Particulate Ag also showed a wide range in concentration, reflecting pristine background conditions to Ag-laden discharge effluents. Upstream particulate Ag concentrations, as for all the other Ag fractions, fell within a narrow range, 0.2 to $1.7 \mu \mathrm{g} / \mathrm{g} \mathrm{Ag}$. Downstream of effluent inputs, the range was higher, 0.5 to $10 \mu \mathrm{g} / \mathrm{g}$, again reflecting the higher $\mathrm{Ag}$ levels of the wastewater discharge. The average log particle-water partition coefficient $\left(K_{\mathrm{d}}\right)$ for all the sites, using the filtered $\mathrm{Ag}$ concentrations and direct particulate $\mathrm{Ag}$ measurements, was $5.7 \pm 0.5$, similar to that of previous freshwater and estuarine water studies [4].

It is important to note that the direct Ag measurements of suspended particles (expressed in ng/L) occasionally exceeded that obtained for total Ag in an unfiltered water sample. This apparent discrepancy is due to the differences in sample prep- aration techniques used for the two measurements. The direct particulate Ag determinations were conducted as a total digestion of the particulate phase. Silver measurements of unfiltered samples were conducted using less harsh sample pretreatment (acidification to $\mathrm{pH} \sim 1.5$, ultrasonification, and $\mathrm{UV}$ oxidation), which in some cases will not liberate all the metal present in the suspended particulate phase. This latter treatment most likely liberates all surface-adsorbed Ag but will not leach Ag from within the interior of some particle phases. A comparison between these two determinations of particulate Ag (i.e., direct vs by difference, not shown) shows good agreement, within the error of the determinations.

\section{Chemical and phase speciation of silver}

Recent studies have shown that the form of Ag that is toxic to freshwater fish is the free $\mathrm{Ag}$ ion, $\mathrm{Ag}^{+}$[21-23]. In order to estimate Ag toxicity, chemical speciation models with only inorganic ions present had previously been considered for oxic conditions [e.g., 24]. Shown in Figure 5A is a prediction of the inorganic speciation of Ag for the study sites where complexation with reduced sulfur species (which were not measured) has been excluded. These estimates were made using formation constants between the major ions and $\mathrm{Ag}$ from Morel and Hering [25] and the 0.1- $\mu \mathrm{m}$ filtered Ag concentrations and ancillary water chemistry data from Table 1 and Appendix 2. This simplified modeling effort predicts that free silver ion, $\mathrm{Ag}^{+}$, would indeed be the major solution form of $\mathrm{Ag}$ in many cases (Fig. 5A).

However, it is now well accepted that chemical speciation calculations for $\mathrm{Ag}$ in natural waters are not realistic without including complexation by reduced sulfur ligands [e.g., 26]. While we do not have any direct information on the complexation of $\mathrm{Ag}$ by reduced sulfur at these sites, compelling arguments can be made in favor of this speciation from recent literature information. First, the highest $0.45-\mu \mathrm{m}$ filter-passing Ag concentration was $3 \mathrm{nM}$, a concentration well below recent measurements of the concentration of reduced sulfur species in aquatic environments [e.g., 26-28]. Second, recent studies of the complexation of Ag by natural organic ligands suggest that conditional stability constants are greater than $\log K_{\text {cond }}$ of 12 [29]. Hence, in the presence of only a few nM of reduced sulfur species, the concentration of all inorganic Ag ions, including the free ion, would be reduced to much less than $1 \%$ of the total Ag concentration in the filter-passing phase in most of these waters [30,31]. The concentration of total reduced sulfur in fresh and estuarine waters is typically more than 10 $\mathrm{nM}$ and often more than $100 \mathrm{nM}$ [e.g., 26,27,30,31]. Thus, we would anticipate Ag to occur as Ag sulfide and/or thiolate, of which a large fraction is expected to be present in colloidal and particulate phases.

Previous studies had demonstrated that 15 to $70 \%$ of the conventionally defined dissolved, 0.45- $\mu \mathrm{m}$ filter-passing Ag was actually bound to a colloidal phase in river and estuarine waters of Texas [4]. A large colloidal component of filterpassing Ag was also found in river waters of Colorado. Only 10 to $40 \%$ of the dissolved $(\leq 0.45 \mu \mathrm{m}) \mathrm{Ag}$ was in fractions smaller than $3 \mathrm{kDa}$ (Fig. 5B). Thus, the major fraction of the $\mathrm{Ag}$ was in the colloidal phase. This finding contradicts the results from thermodynamic model calculations using only inorganic ligands (Fig. 5A) that ignore the important role in $\mathrm{Ag}$ cycling of thiols and sulfides, both existing in colloidal and low-molecular-weight fractions in fresh and estuarine waters [26-28,32]. The close similarity between $\mathrm{Cu}$ (as $\mathrm{Cu}-\mathrm{I})$ and $\mathrm{Ag}$ 


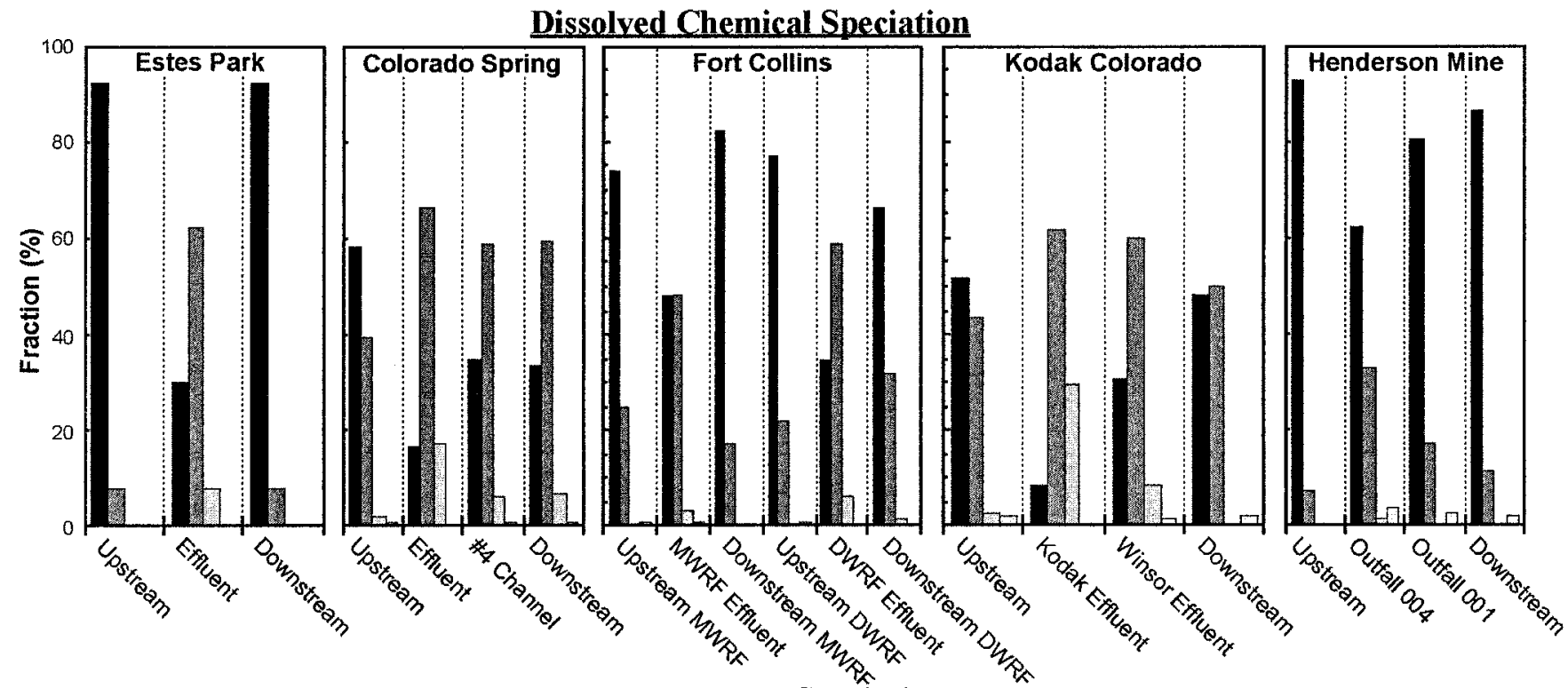

Dissolved Phase Speciation

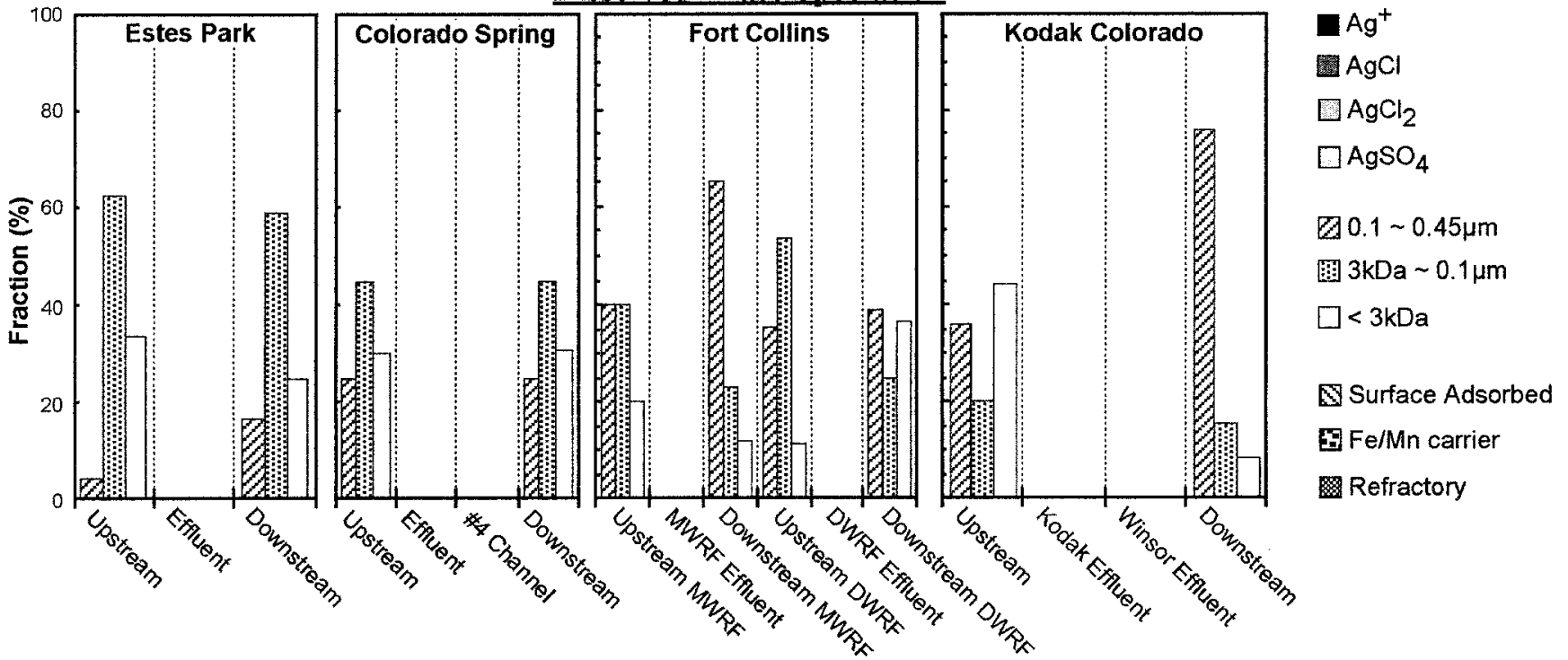

Solid Phase Speciation

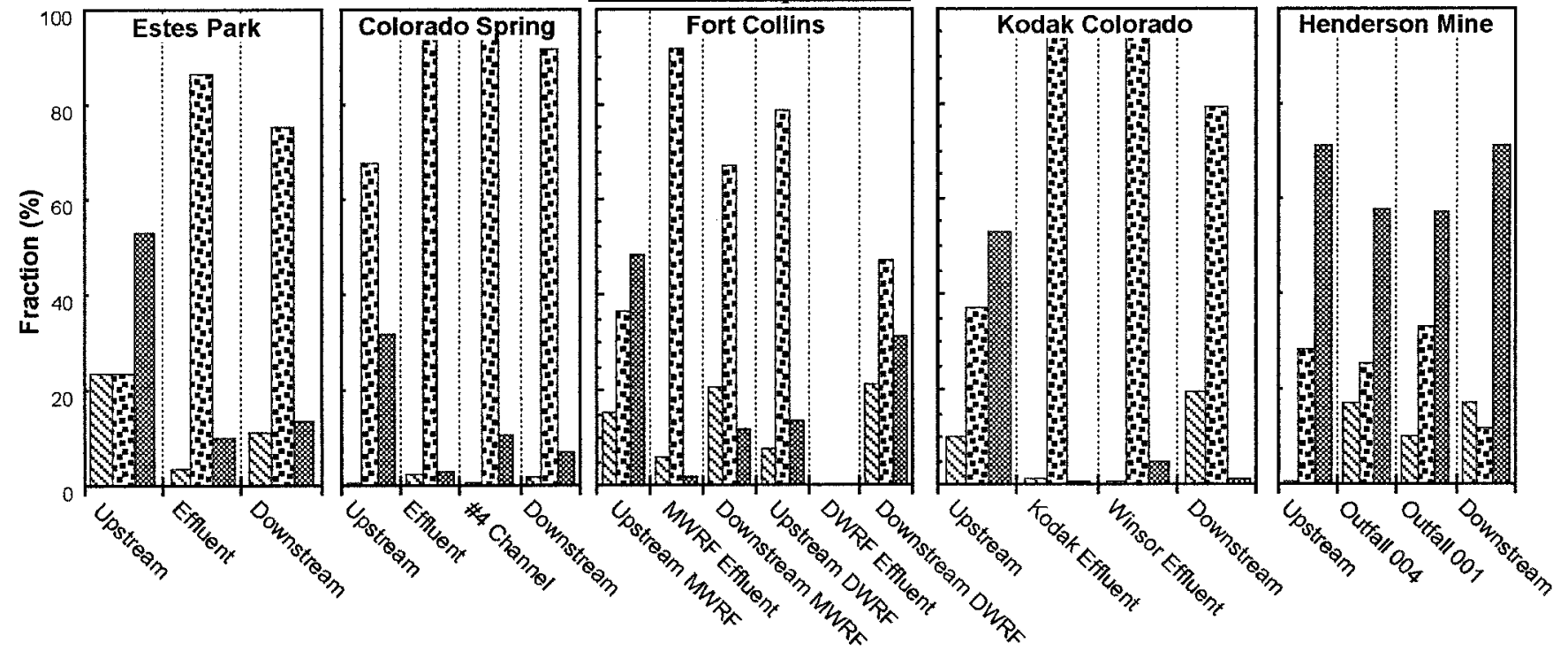

Fig. 5. Chemical and phase speciation of Ag in Colorado, USA, watersheds. MWRF = Mulberry Water Treatment Facility; DWRF $=$ Drake Water Treatment Facility. Sample locations are given in Table 1. 
and the close relationships between $\mathrm{Cu}$ and reduced sulfur species found in surface waters [e.g., 33,34] make this even more likely. Therefore, thermodynamic calculations without proper ligand characterization can be misleading. If $\mathrm{Ag}$ would occur predominantly as $\mathrm{Ag}^{+}$and $\mathrm{AgCl}$ species, which would readily pass through a $3-\mathrm{kDa}$ filter, no colloidal Ag phase should exist.

For particulate Ag, the major fractions were contained within a Fe-Mn oxyhydroxide/sulfide phase, except for the Henderson Mine site, where most Ag resided in a refractory phase (Fig. 5C). In previous studies [4], a close relationship between $\mathrm{Ag}$ and $\mathrm{Fe}$ in colloidal and particulate phases was found, suggesting common carrier phases or surface complexes, most likely sulfhydryl groups. Here, Ag concentrations in colloids were also similar to those in particulate matter (expressed as $\mu \mathrm{g} / \mathrm{g}$ ), indicating similar complexation capacities (Fig. 6A). This similarity in colloidal and particulate silver concentration indicates that its carrier phase is distributed over a continuum of particle sizes, ranging from microparticles to macromolecules. Even though Wen et al. [4] found a linear relationship between particulate and colloidal Ag concentrations (in $\mu \mathrm{g} / \mathrm{g}$ ) for Texas watersheds, their values were not distributed along a 1:1 line (the slope was different from 1). Thus, the agreement between particulate $\mathrm{Ag}$ and colloidal $\mathrm{Ag}$ is superior to that of Texas waters [4]. This could also be due to the narrower colloidal size range of $0.1 \mu \mathrm{m}$ to $3 \mathrm{kDa}$, which could better constrain the colloidal size range relevant for both $\mathrm{Ag}$, organic carbon, and reduced sulfur. The more consistent relationship could also be related to the differences in watersheds or due to analytical improvements. In any case, the difference in particulate Ag concentrations retained by the two filters (0.4- vs $0.1-\mu \mathrm{m}$ pore size) is small.

Colloidal Ag ( $3 \mathrm{kDa}-0.1 \mu \mathrm{m})$, as a fraction of the total 0.1 $\mu \mathrm{m}$ filter-passing concentration, partitioned very similarly to that of colloidal carbon in the same size fraction (Fig. 6B). Such a similarity in the colloidal partitioning was shown previously [4] for Texas watersheds but is much better for the Colorado rivers. Such a relationship would be expected if functional groups with strong affinity for Ag were evenly distributed over the whole molecular-weight or size spectrum of colloidal aggregates [e.g., 26].

\section{SUMMARY AND CONCLUSIONS}

Teflon is the preferred material for storage bottles, as it does not introduce any concentration bias during storage for low-level Ag determinations if proper cleaning, storage, and sample pretreatment methods are applied. Silver could be quantitatively recovered after storage periods of three months or greater when samples were acidified, sonicated, and UV irradiated before analysis. While some $\mathrm{Ag}$ in acidified natural waters may adsorb onto Teflon bottle walls, it can be completely recovered through UV irradiation of the sample water combined with sonification. Ultraviolet irradiation digestion was also required for $\mathrm{Ag}$ analysis in concentrated colloidal solutions. With the exception of PVC, other plastics can be used for short-term storage bottles without fear of contamination. However, these bottles do not pass UV irradiation and therefore preclude a UV-digestion step to remove any absorbed $\mathrm{Ag}$ on the bottle walls. The need for UV digestion strongly suggests that Ag sorbs as a surface-active colloidal macromolecular organic species.

In surface water samples from Colorado, Ag concentrations in unfiltered samples spanned more than four orders of magnitude, from a high of $33,400 \mathrm{ng} / \mathrm{L}$ to a low of $1.8 \mathrm{ng} / \mathrm{L}$, with
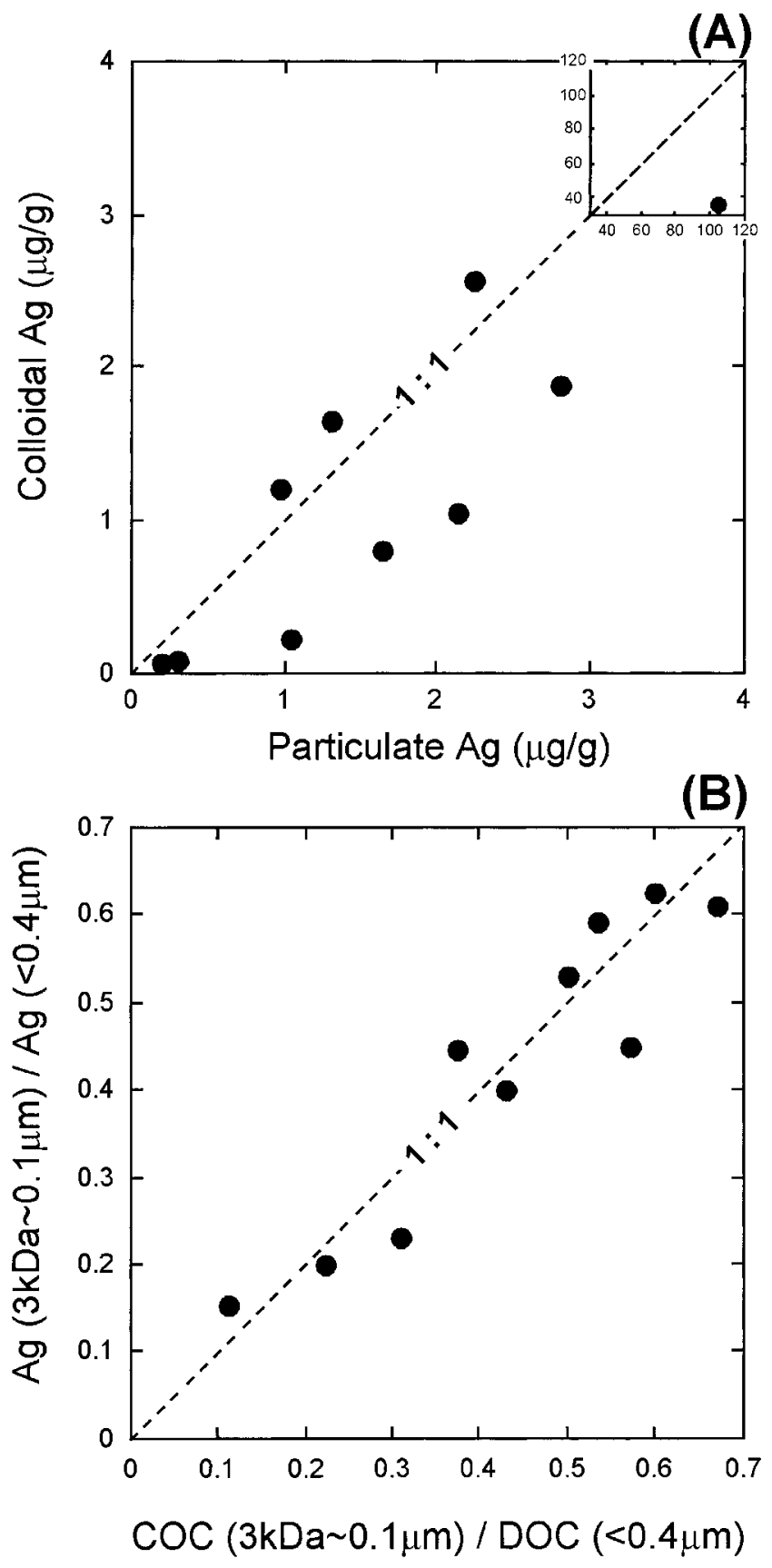

Fig. 6. (A) Correlation between the Ag concentrations in colloidal matter and the Ag concentrations in suspended matter. (B) Correlation between colloidal $\mathrm{Ag}$ as a fraction of the total filter-passing $\mathrm{Ag}$ and colloidal organic carbon (COC) concentration as a fraction of dissolved organic carbon (DOC).

upstream concentrations falling within a fairly narrow range, 3.1 to $21 \mathrm{ng} / \mathrm{L}$ and downstream concentrations spanning a considerably broader range of 2.8 to $1,107 \mathrm{ng} / \mathrm{L}$. The highest downstream concentrations were associated with the highest Ag levels in wastewater effluents. Silver concentrations in filtered samples, in general, mirrored those observed in the unfiltered samples, but at lower overall concentration levels. In all cases, the concentration of Ag observed in the $0.1-\mu \mathrm{m}$ filtered fraction was less than that observed in the $0.45-\mu \mathrm{m}$ filter-passing fraction because of the existence of a colloidal $\mathrm{Ag}$ fraction. The highest $0.1-\mu \mathrm{m}$ filter-passing concentration of $70 \mathrm{ng} / \mathrm{L}$ was observed downstream from the Kodak plant 
effluent, which was well below the silver criteria (e.g., the chronic value of $190 \mathrm{ng} / \mathrm{L}$ set by Colorado).

Thermodynamic modeling efforts suggest that particulate matter and chloride concentrations would exert dominant controls on the phase and inorganic solution speciation of $\mathrm{Ag}$ in the absence of reduced sulfur species. The dominant factor appears to be the total suspended solids concentration, as evidenced by the high percentages of total Ag present in the particulate fraction at most sites. In the absence of sulfides and thiols, chloride species of Ag would be most important in the effluent-affected river waters. However, reduced sulfur species are abundant in freshwater environments and occur in particulate, colloidal, and dissolved fractions [26,27,34] at greater than $10 \mathrm{nM}$. Reduced sulfur species were not measured, but since we found that 15 to $90 \%$ of the conventionally defined dissolved $\mathrm{Ag}$ was actually bound to a colloidal phase $(\geq 3 \mathrm{kDa})$ and not present in ionic forms, even the small calculated free Ag concentrations must be an overestimate. The overestimate could be orders of magnitude if the free Ag concentration is controlled by reduced sulfur [26,30]. Thus, our finding of major fractions of filter-passing $\mathrm{Ag}$ being associated with colloidal fractions requires the consideration of stronger ligands in the colloidal and particulate phases. Since major fractions of particulate $\mathrm{Ag}$ were contained within a $\mathrm{Fe}-\mathrm{Mn}$ oxyhydroxide/sulfide phase, particulate and colloidal Ag concentrations $(\mu \mathrm{g} / \mathrm{g})$ were similar; this suggests common surface complexes, most likely sulfhydryl groups, such as sulfidic and thiolic functional groups. The close agreement between the fraction of colloidal $\mathrm{Ag}$ and fraction of colloidal organic carbon in the filter-passing phase strongly suggests a major role of macromolecular organic matter in Ag speciation.

Acknowledgement-We appreciate the help of Ron Lehman, Joe Gorsuch, and Steve Noble with sampling efforts and Kevin Yeager with the preparation of figures. This work was in part supported by grants from the International Imaging Industries Association, the Harbor Processes Program of the Office of Naval Research (N00014-99-10037), and the Texas Institute of Oceanography.

\section{REFERENCES}

1. Hogstrand C, Wood CM. 1998. Towards a better understanding of the bioavailability, physiology, and toxicity of silver in fish: Implications for water quality criteria. Environ Toxicol Chem 17: 547-561.

2. U.S. Environmental Protection Agency. 1999. National recommended water quality criteria correction. EPA-822-Z-99-001. Washington, DC.

3. Wen LS, Stordal MC, Tang D, Gill GA, Santschi PH. 1996. An ultraclean cross-flow ultrafiltration technique for the study of trace metal phase speciation in seawater. Mar Chem 55:129-152.

4. Wen LS, Santschi PH, Gill GA, Paternostro CL, Lehman RD. 1997. Colloidal and particulate silver in river and estuarine waters of Texas. Environ Sci Technol 31:723-731.

5. Wen LS, Santschi PH, Paternostro C, Gill G. 1999. Estuarine trace metal distributions in Galveston Bay I: Importance of colloidal forms in the speciation of the dissolved phase. Mar Chem 63:185-212.

6. Martin JH, Knauer GA, Gordon RM. 1983. Silver distributions and fluxes in northeast Pacific waters. Nature 305:306-309.

7. Santschi PH, Lenhart J, Honeyman BD. 1997. Heterogeneous processes affecting trace contaminant distribution in estuaries: The role of natural organic matter. Mar Chem 58:99-125.

8. Sañudo-Wilhelmy SA, Flegal AR. 1992. Anthropogenic silver in the Southern California Bight: A new tracer of sewage in coastal waters. Environ Sci Technol 26:2147-2151.

9. Benoit G, Oktay-Marshall SD, Cantu A, Hood EM, Coleman CH, Corapcioglu MO, Santschi PH. 1994. Partitioning of $\mathrm{Cu}, \mathrm{Pb}, \mathrm{Ag}$, $\mathrm{Zn}, \mathrm{Fe}, \mathrm{Al}$, and $\mathrm{Mn}$ between filter-retained particles, colloids, and solution in six Texas estuaries. Mar Chem 45:307-336.

10. Smith GJ, Flegal AR. 1993. Temporal and spatial variations in the cycling of silver within San Francisco Bay estuarine waters. Estuaries 16:547-558.

11. Shafer MM, Armstrong DE, Walker MT, Overdier JT. 1994. Par- titioning and fate of silver in background streams and effluentreceiving streams. Proceedings, 2nd International Argentum Conference, Madison, WI, USA, September 11-14, pp 99-105.

12. Benoit G. 1994. Clean technique measurement of $\mathrm{Pb}, \mathrm{Ag}$, and Cd, in freshwater: A redefinition of metal pollution. Environ Sci Technol 28:1987-1991.

13. Santschi PH. 1988. Factors controlling the biogeochemical cycles of trace elements in fresh and marine waters as revealed by artificial radioisotopes. Limnol Oceanogr 33:848-866.

14. Santschi PH, Nyffeler UP, Anderson RF, Schiff SL, O'Hara P, Hesslein RH. 1986. Response of radioactive trace metals to acidbase titrations in controlled experimental ecosystems: Evaluation of transport parameters for application to whole-lake radiotracer experiments. Can J Fish Aquat Sci 43:60-77.

15. American Public Health Association, American Water Works Association, Water Pollution Control Federation. 1992. Standard Methods for the Examination of Water and Wastewater, 18th ed. American Water Works Association, Washington, DC, p 1100.

16. Alfassi ZB. 1994. Determination of Trace Elements. VCH, Weinheim, Germany.

17. Figura P, McDuffie B. 1980. Determination of labilities of soluble trace metal species in aqueous environmental samples by anodic stropping voltammetry and chelex column and batch methods. Anal Chem 52:1433-1439.

18. Quentel F, Madec C, Courtot-Coupez J. 1985. Influence of dissolved organic matter on the lead determination in seawater by anodic stripping voltammetry. Water Res 20:325-333.

19. Heithmar E, Hinneres T, Rowan J, Riviello J. 1990. Minimization of interferences in inductively coupled plasma mass spectrometry using on-line preconcentration. Anal Chem 62:857-864.

20. Ostapczuk P. 1993. Present potentials and limitations in the determination of trace elements by potentiometric stripping analysis. Anal Chim Acta 273:35-40.

21. Wood CM, Munger RS, Hogstrand C. 1993. The physiological mechanisms of toxicity of silver and other metals to freshwater fish. Proceedings, 1st International Argentum Conference, Madison, WI, USA, August 8-10, pp 89-92.

22. Wood CM, Munger RS, Galvez FG, Hogstrand C. 1994. The physiology of silver toxicity in freshwater fish. Proceedings, 2nd International Argentum Conference, Madison, WI, USA, September 11-14, pp 109-113.

23. Wood C, Morgan I, Galvez F, Hogstrand C, 1995. The toxicity of silver in fresh and marine waters. Proceedings, 3rd International Argentum Conference, Washington, DC, USA, August 69, pp 51-59.

24. Andren AW, Wingert-Runge B, Sedlak D. 1995. The occurrence and behavior of silver in natural waters. Proceedings, 3rd International Argentum Conference, Washington, DC, August 6-9, University of Wisconsin, Madison, Wisconsin, USA, pp 7-9.

25. Morel FMM, Hering JG. 1993. Principles and Applications of Aquatic Chemistry. John Wiley, New York, NY, USA.

26. Bell RA, Kramer JR. 1999. Structural chemistry and geochemistry of silver-sulfur compounds: Critical review. Environ Toxicol Chem 18:9-22.

27. Tang D, Santschi PH, Hung C-C, Warnken K. 2000. The distribution of biogenic thiols in surface waters of Galveston Bay. Limnol Oceanogr 45:1289-1297.

28. Tang D, Santschi PH. 2000. Sensitive determination of dissolved sulfide in estuarine water by solid phase extraction and highperformance liquid chromatography detection of methylene blue. J Chromatogr A 883:305-309.

29. Herrin RT, Anders AW, Shafer MM, Armstrong DE. 2001. Determination of silver speciation in natural waters. 2. Binding strength of silver ligands in surface waters. Environ Sci Technol 35:1959-1966.

30. Adams NWH, Kramer JR. 1999. Silver speciation in wastewater effluent, surface waters, and pore waters. Environ Toxicol Chem 18:2667-2673.

31. Adams NWH, Kramer JR. 1999. Determination of silver speciation in wastewater and receiving waters by competitive ligand equilibration/solvent extraction. Environ Toxicol Chem 18:26742680.

32. Tang D, Wen L-S, Santschi PH. 2000. Analysis of biogenic thiols in natural samples by HPLC separation and fluorescence detection with ammonium 7-fluorobenzo-2-oxa-1,3-diazole-4-sulfonate (SBD-F). Anal Chim Acta 408:299-307.

33. Leal MFC, van den Berg CMG. 1998. Evidence for strong copper (I) complexation by organic ligands in seawater. Aquat Geochem 4:49-75.

34. Tang D, Warnken KW, Santschi PH. 2001. Organic complexation of copper in surface waters of Galveston Bay. Limnol Oceanogr 46:321-330. 
Appendix 1. Concentration of $\mathrm{Ag}(\mu \mathrm{g} / \mathrm{L})$ in various acidified solutions in sample bottles of different materials as a function of storage time. The bottle materials investigated included FEP Teflon ${ }^{\circledR}$, polyvinylchloride (PVC), polycarbonate (PC), polypropylene (PP), low- and high-density polyethylene (LDPE and HDPE), and fluorinated polyethylene (FLPE)

A. double-distilled water

\begin{tabular}{|c|c|c|c|c|c|c|c|c|}
\hline \multirow{2}{*}{$\begin{array}{l}\text { Bottle } \\
\text { type }\end{array}$} & \multirow{2}{*}{$\begin{array}{c}\text { Concn. (ml) } \\
\left(\mathrm{HNO}_{3} / \mathrm{L}\right. \\
\text { sample) }\end{array}$} & \multicolumn{7}{|c|}{ Storage time (h) } \\
\hline & & 4 & 12 & 24 & 48.5 & 71.5 & 95.5 & 192 \\
\hline \multirow[t]{5}{*}{ PVC } & 0 & 0.90 & 0.48 & 0.03 & 0.02 & 0.01 & 0.01 & 0.00 \\
\hline & 1 & 0.97 & 0.66 & 0.09 & 0.04 & 0.04 & 0.03 & 0.02 \\
\hline & 2 & 0.95 & 0.69 & 0.18 & 0.08 & 0.06 & 0.05 & 0.04 \\
\hline & 4 & 1.00 & 0.98 & 0.96 & 0.93 & 0.90 & 0.89 & 0.78 \\
\hline & 8 & 1.00 & 1.01 & 1.00 & 1.01 & 1.00 & 1.01 & 1.00 \\
\hline \multirow[t]{5}{*}{$\mathrm{PC}$} & 0 & 1.01 & 1.01 & 1.00 & 0.98 & 0.92 & 0.89 & 0.86 \\
\hline & 1 & 1.01 & 1.00 & 1.00 & 1.00 & 1.01 & 1.02 & 1.00 \\
\hline & 2 & 1.01 & 1.01 & 1.00 & 1.01 & 1.03 & 1.00 & 1.00 \\
\hline & 4 & 1.00 & 1.01 & 1.00 & 1.04 & 1.02 & 1.03 & 1.00 \\
\hline & 8 & 1.00 & 1.01 & 1.00 & 1.01 & 1.00 & 1.01 & 1.00 \\
\hline \multirow[t]{5}{*}{ PP } & 0 & 1.01 & 1.00 & 1.00 & 1.00 & 1.01 & 1.00 & 1.00 \\
\hline & 1 & 1.04 & 1.01 & 1.00 & 1.01 & 1.03 & 1.00 & 1.00 \\
\hline & 2 & 1.01 & 1.00 & 1.00 & 1.01 & 1.00 & 1.01 & 1.00 \\
\hline & 4 & 1.00 & 1.01 & 1.00 & 1.01 & 1.00 & 1.00 & 1.00 \\
\hline & 8 & 1.00 & 1.01 & 1.00 & 1.00 & 1.00 & 1.01 & 1.00 \\
\hline \multirow[t]{5}{*}{ HDPE } & 0 & 1.01 & 0.99 & 0.99 & 0.99 & 0.99 & 0.99 & 0.99 \\
\hline & 1 & 1.00 & 1.01 & 1.00 & 1.01 & 1.00 & 1.01 & 1.00 \\
\hline & 2 & 1.00 & 0.98 & 0.99 & 1.00 & 0.99 & 1.00 & 1.00 \\
\hline & 4 & 1.00 & 1.00 & 0.99 & 0.99 & 0.99 & 0.98 & 1.00 \\
\hline & 8 & 1.00 & 1.01 & 1.02 & 1.03 & 1.01 & 1.03 & 1.00 \\
\hline \multirow[t]{5}{*}{ LDPE } & 0 & 1.00 & 1.01 & 1.00 & 1.01 & 1.02 & 1.00 & 1.02 \\
\hline & 1 & 1.00 & 1.01 & 0.99 & 0.99 & 0.99 & 0.99 & 0.99 \\
\hline & 2 & 1.02 & 0.99 & 0.97 & 1.02 & 0.96 & 1.00 & 0.98 \\
\hline & 4 & 1.03 & 1.01 & 1.00 & 1.01 & 1.00 & 1.01 & 1.00 \\
\hline & 8 & 1.00 & 1.01 & 1.02 & 1.01 & 1.03 & 1.00 & 1.00 \\
\hline \multirow[t]{5}{*}{ FLPE } & 0 & 1.02 & 0.99 & 0.99 & 0.97 & 0.99 & 1.01 & 1.00 \\
\hline & 1 & 0.99 & 1.00 & 0.99 & 0.99 & 0.99 & 1.00 & 1.00 \\
\hline & 2 & 0.99 & 1.00 & 0.99 & 0.98 & 0.99 & 1.00 & 1.00 \\
\hline & 4 & 0.99 & 1.00 & 0.99 & 0.98 & 0.99 & 1.00 & 0.99 \\
\hline & 8 & 1.00 & 1.01 & 1.00 & 1.00 & 1.00 & 1.00 & 1.01 \\
\hline \multirow[t]{5}{*}{ Teflon } & 0 & 1.01 & 1.01 & 1.00 & 1.01 & 1.00 & 1.01 & 1.01 \\
\hline & 1 & 1.00 & 1.00 & 0.99 & 0.99 & 0.98 & 1.00 & 1.00 \\
\hline & 2 & 1.00 & 1.01 & 1.00 & 1.00 & 1.00 & 1.00 & 1.00 \\
\hline & 4 & 1.00 & 0.99 & 0.99 & 1.01 & 0.99 & 0.99 & 0.99 \\
\hline & 8 & 1.01 & 1.01 & 1.03 & 1.00 & 1.00 & 1.00 & 1.00 \\
\hline
\end{tabular}

B. River water

\begin{tabular}{|c|c|c|c|c|c|c|c|}
\hline \multirow{2}{*}{$\begin{array}{l}\text { Bottle } \\
\text { type }\end{array}$} & \multirow{2}{*}{$\begin{array}{c}\text { Concn. (ml) } \\
\left(\mathrm{HNO}_{3} / \mathrm{L}\right. \\
\text { sample) }\end{array}$} & \multicolumn{6}{|c|}{ Storage time (h) } \\
\hline & & 0 & 4 & 24 & 48.5 & 96 & 192.5 \\
\hline \multirow[t]{5}{*}{ PVC } & 0 & 0.70 & 0.64 & 0.43 & 0.25 & 0.18 & 0.17 \\
\hline & 1 & 0.69 & 0.67 & 0.63 & 0.36 & 0.24 & 0.20 \\
\hline & 2 & 0.71 & 0.70 & 0.68 & 0.54 & 0.31 & 0.24 \\
\hline & 4 & 0.70 & 0.70 & 0.70 & 0.69 & 0.70 & 0.70 \\
\hline & 8 & 0.70 & 0.70 & 0.70 & 0.70 & 0.70 & 0.70 \\
\hline \multirow[t]{5}{*}{$\mathrm{PC}$} & 0 & 0.70 & 0.65 & 0.46 & 0.30 & 0.25 & 0.20 \\
\hline & 1 & 0.71 & 0.71 & 0.71 & 0.68 & 0.65 & 0.55 \\
\hline & 2 & 0.70 & 0.70 & 0.70 & 0.70 & 0.70 & 0.70 \\
\hline & 4 & 0.70 & 0.70 & 0.70 & 0.70 & 0.71 & 0.70 \\
\hline & 8 & 0.70 & 0.70 & 0.70 & 0.70 & 0.70 & 0.70 \\
\hline \multirow[t]{5}{*}{ PP } & 0 & 0.69 & 0.68 & 0.46 & 0.35 & 0.29 & 0.24 \\
\hline & 1 & 0.69 & 0.69 & 0.70 & 0.71 & 0.70 & 0.70 \\
\hline & 2 & 0.70 & 0.70 & 0.71 & 0.70 & 0.71 & 0.70 \\
\hline & 4 & 0.70 & 0.70 & 0.70 & 0.70 & 0.70 & 0.70 \\
\hline & 8 & 0.70 & 0.70 & 0.70 & 0.70 & 0.70 & 0.70 \\
\hline \multirow[t]{5}{*}{ HDPE } & 0 & 0.69 & 0.65 & 0.44 & 0.29 & 0.23 & 0.19 \\
\hline & 1 & 0.69 & 0.69 & 0.71 & 0.70 & 0.70 & 0.71 \\
\hline & 2 & 0.70 & 0.70 & 0.70 & 0.70 & 0.70 & 0.70 \\
\hline & 4 & 0.70 & 0.70 & 0.70 & 0.70 & 0.71 & 0.70 \\
\hline & 8 & 0.70 & 0.70 & 0.70 & 0.70 & 0.70 & 0.70 \\
\hline \multirow[t]{5}{*}{ LDPE } & 0 & 0.68 & 0.67 & 0.48 & 0.39 & 0.31 & 0.26 \\
\hline & 1 & 0.68 & 0.68 & 0.70 & 0.70 & 0.70 & 0.70 \\
\hline & 2 & 0.70 & 0.70 & 0.70 & 0.70 & 0.70 & 0.70 \\
\hline & 4 & 0.70 & 0.70 & 0.70 & 0.70 & 0.70 & 0.70 \\
\hline & 8 & 0.70 & 0.70 & 0.70 & 0.70 & 0.70 & 0.70 \\
\hline \multirow[t]{5}{*}{ FLPE } & 0 & 0.68 & 0.67 & 0.57 & 0.51 & 0.42 & 0.39 \\
\hline & 1 & 0.68 & 0.68 & 0.70 & 0.70 & 0.70 & 0.70 \\
\hline & 2 & 0.70 & 0.70 & 0.72 & 0.72 & 0.70 & 0.70 \\
\hline & 4 & 0.69 & 0.69 & 0.70 & 0.70 & 0.70 & 0.70 \\
\hline & 8 & 0.70 & 0.70 & 0.70 & 0.71 & 0.70 & 0.71 \\
\hline \multirow{5}{*}{ Teflon } & 0 & 0.70 & 0.69 & 0.64 & 0.58 & 0.55 & 0.53 \\
\hline & 1 & 0.70 & 0.70 & 0.70 & 0.70 & 0.70 & 0.69 \\
\hline & 2 & 0.70 & 0.70 & 0.70 & 0.70 & 0.70 & 0.70 \\
\hline & 4 & 0.70 & 0.70 & 0.70 & 0.70 & 0.71 & 0.70 \\
\hline & 8 & 0.70 & 0.70 & 0.70 & 0.70 & 0.70 & 0.70 \\
\hline
\end{tabular}


Appendix 2. Additional water chemistry parameters; all study sites are located in Colorado, USA (see Table 1 for locations)

\begin{tabular}{|c|c|c|c|c|c|c|c|}
\hline $\begin{array}{l}\text { Sampling } \\
\text { site }\end{array}$ & $\begin{array}{c}\mathrm{SO}_{4}^{2-} \\
(\mathrm{mg} / \mathrm{L})\end{array}$ & $\begin{array}{c}\mathrm{NO}_{3}^{-} \\
(\mathrm{mg} / \mathrm{L})\end{array}$ & $\begin{array}{l}\mathrm{HPO}_{4}^{2-} \\
(\mathrm{mg} / \mathrm{L})\end{array}$ & $\begin{array}{c}\mathrm{Na}^{+} \\
(\mathrm{mg} / \mathrm{L})\end{array}$ & $\begin{array}{c}\mathrm{K}^{+} \\
(\mathrm{mg} / \mathrm{L})\end{array}$ & $\begin{array}{l}\mathrm{Mg}^{2+} \\
(\mathrm{mg} / \mathrm{L})\end{array}$ & $\begin{array}{c}\mathrm{Ca}^{2+} \\
(\mathrm{mg} / \mathrm{L})\end{array}$ \\
\hline \multicolumn{8}{|l|}{ Estes Park } \\
\hline Upstream & $2.2 \pm 0.0$ & $0.4 \pm 0.0$ & $<0.5$ & $4.0 \pm 0.3$ & $0.5 \pm 0.0$ & $0.9 \pm 0.0$ & $6.6 \pm 0.0$ \\
\hline Downstream & $40.1 \pm 0.4$ & $0.8 \pm 0.1$ & $<0.5$ & $4.8 \pm 0.3$ & $0.6 \pm 0.0$ & $0.9 \pm 0.1$ & $6.7 \pm 0.1$ \\
\hline Plant & $2.7 \pm 0.1$ & $32 \pm 0$ & $11 \pm 1$ & $51 \pm 1$ & $13 \pm 0$ & $5.3 \pm 0.0$ & $40 \pm 1$ \\
\hline \multicolumn{8}{|l|}{ Henderson Mine } \\
\hline Upstream & $4.3 \pm 0.1$ & $0.8 \pm 0.1$ & $<0.5$ & $1.5 \pm 0.1$ & $0.2 \pm 0.0$ & $0.8 \pm 0.0$ & $14 \pm 1$ \\
\hline Outfall 001 & $593 \pm 6$ & $13 \pm 1$ & $<0.5$ & $320 \pm 6$ & $32 \pm 1$ & $11 \pm 1$ & $53 \pm 1$ \\
\hline Outfall 004 & $204 \pm 3$ & $0.7 \pm 0.0$ & $<0.5$ & $94 \pm 1$ & $5.9 \pm 0.2$ & $9.5 \pm 0.7$ & $50 \pm 1$ \\
\hline Downstream & $230 \pm 9$ & $3.7 \pm 0.1$ & $<0.5$ & $109 \pm 4$ & $9.4 \pm 0.4$ & $3.7 \pm 0.3$ & $55 \pm 2$ \\
\hline \multicolumn{8}{|l|}{ Colorado Springs } \\
\hline Upstream & $87 \pm 16$ & $15 \pm 2$ & $<0.5$ & $34 \pm 1$ & $3.4 \pm 0.2$ & $11 \pm 1$ & $99 \pm 4$ \\
\hline Downstream & $129 \pm 6$ & $38 \pm 1$ & $1.1 \pm 0.8$ & $55 \pm 3$ & $5.8 \pm 0.4$ & $13 \pm 1$ & $85 \pm 2$ \\
\hline Plant & $163 \pm 2$ & $90 \pm 5$ & $1.5 \pm 0.2$ & $80 \pm 0$ & $8.7 \pm 0.0$ & $15 \pm 0$ & $73 \pm 1$ \\
\hline No. 4 channel & $127 \pm 30$ & $36 \pm 1$ & $1.1 \pm 0.4$ & $66 \pm 0$ & $7.0 \pm 0.2$ & $14 \pm 0$ & $83 \pm 5$ \\
\hline \multicolumn{8}{|l|}{ Kodak } \\
\hline Upstream & $499 \pm 5$ & $8.4 \pm 0.1$ & $<0.5$ & $79 \pm 2$ & $3.9 \pm 0.3$ & $67 \pm 4$ & $245 \pm 7$ \\
\hline Downstream & $513 \pm 13$ & $17 \pm 5$ & $<0.5$ & $89 \pm 4$ & $5.5 \pm 0.4$ & $66 \pm 5$ & $231 \pm 5$ \\
\hline KCD effluent & $505 \pm 29$ & $170 \pm 6$ & $<0.5$ & $100 \pm 1$ & $74 \pm 8$ & $26 \pm 2$ & $81 \pm 6$ \\
\hline Windsor effluent & $491 \pm 9$ & $34 \pm 1$ & $3.3 \pm 0.7$ & $330 \pm 12$ & $8.9 \pm 0.3$ & $64 \pm 1$ & $261 \pm 8$ \\
\hline \multicolumn{8}{|l|}{ Fort Collins } \\
\hline \multicolumn{8}{|l|}{ Upstream of } \\
\hline MWRF effluent & $80 \pm 9$ & $38 \pm 4$ & $3.4 \pm 0.6$ & $32 \pm 3$ & $6.4 \pm 0.3$ & $12 \pm 1$ & $96 \pm 5$ \\
\hline \multicolumn{8}{|l|}{ Downstream of } \\
\hline MWRF & $26 \pm 3$ & $2.5 \pm 0.9$ & $<0.5$ & $8.8 \pm 0.6$ & $1.6 \pm 0.3$ & $6.8 \pm 0.8$ & $48 \pm 4$ \\
\hline \multicolumn{8}{|l|}{ Upstream of } \\
\hline DWRF & $53 \pm 0$ & $4.4 \pm 1.9$ & $<0.5$ & $19 \pm 2$ & $1.5 \pm 0.2$ & $10 \pm 0$ & $63 \pm 6$ \\
\hline DWRF effluent & $73 \pm 6$ & $93 \pm 4$ & $8.6 \pm 0.8$ & $50 \pm 3$ & $8.5 \pm 0.5$ & $23 \pm 1$ & $88 \pm 5$ \\
\hline \multicolumn{8}{|l|}{ Downstream of } \\
\hline DWRF & $45 \pm 4$ & $3.7 \pm 0.4$ & $<0.5$ & $41 \pm 2$ & $3.7 \pm 0.0$ & $42 \pm 3$ & $259 \pm 11$ \\
\hline
\end{tabular}

